\title{
Competências Empreendedoras de Dirigentes que Atuam em Empresas
}

\author{
Intensivas em Tecnologia \\ Entrepreneurial Competences of Directors that Work in Intensive Technology Companies \\ Ricardo Gabriel Danyalgil Junior*1, Chris Herbert Berenguer Pereira ${ }^{1}$, Fernando Gomes de Paiva Junior ${ }^{1}$ \\ ${ }^{1}$ Universidade Federal de Pernambuco, Pernambuco, Brasil.
}

\begin{tabular}{|c|c|}
\hline I NFOARTIGO & RESUMO \\
\hline $\begin{array}{l}\text { Palavras-chave: } \\
\text { Empreendedorismo, } \\
\text { Competências } \\
\text { empreendedoras, } \\
\text { Empresas de base } \\
\text { tecnológica, } \\
\text { Competências } \\
\text { tecnológicas. }\end{array}$ & $\begin{array}{l}\text { Este artigo tem por objetivo a descrição das competências empreendedoras } \\
\text { que surgem na expressão do comportamento de dirigentes que operam em } \\
\text { empresas intensivas em tecnologia localizadas na Região Metropolitana do } \\
\text { Recife (RMR), estado de Pernambuco. Foram investigadas as competências } \\
\text { empreendedoras de oportunidade, conceitual, relacional, administrativa, de } \\
\text { comprometimento e de equilíbrio entre trabalho e vida pessoal. A pesquisa é } \\
\text { qualitativa e contempla a análise de conteúdo temática com base em } \\
\text { entrevistas com empreendedores que operam em empresas de médio e grande } \\
\text { porte. Os resultados revelam a relevância das competências conceituais, } \\
\text { administrativas e relacionais, além da emergência de competências } \\
\text { tecnológicas como categoria de análise para auxiliar futuros estudos sobre } \\
\text { competências empreendedoras. }\end{array}$ \\
\hline ARTICLEINFO & A B S T R AC T \\
\hline $\begin{array}{l}\text { Keywords: } \\
\text { Entrepreneurship, } \\
\text { Entrepreneurial skills, } \\
\text { Technology-based } \\
\text { companies, } \\
\text { Technological skills. }\end{array}$ & $\begin{array}{l}\text { This article aims at the descriptive analysis of entrepreneurial skills that } \\
\text { emerge in the expression of managers behavior who operate in technology- } \\
\text { intensive companies located in the Metropolitan Region of Recife (RMR), } \\
\text { state of Pernambuco. Entrepreneurial skills of opportunity, conceptual, } \\
\text { relational, administrative, commitment and balance between work and } \\
\text { personal life were investigated. The research is qualitative and includes } \\
\text { thematic content analysis based on interviews with entrepreneurs operating in } \\
\text { medium and large companies. The results reveal the relevance of conceptual, } \\
\text { administrative, and relational skills, in addition to the emergence of } \\
\text { technological skills. }\end{array}$ \\
\hline
\end{tabular}

\section{INTRODUÇÃO}

Diante do cenário hipercompetitivo evidenciado na pós-modernidade, os indivíduos enfretam a necessidade de aperfeiçoamento profissional contínuo (CLEARY, 2017), uma vez que eles buscam alternativas satisfatórias de gestão para seus bens e serviços, em que emerge a possibilidade de desenvolvimento social, econômico e cultural frente a cenários de carreira não-lineares nos quais a mobilidade inerente ao fazer tecnológico demanda a busca por novas formas de expertise oriundas do universo empreendedor (ARTHUR, 2014).

No âmbito das organizações dirigidas para serviços de alta tecnologia e empresas intensivas em conhecimento, a busca por inovação tecnológica e maximização de resultados financeiros se revela por meio de indivíduos especializados em desenvolvimento de competências de cunho oportunístico, relacional, conceitual,

\footnotetext{
* Correspondência para autor:

ricdanyalgil@gmail.com (Danyalgil JR, R.G.) (ORCID: 0000-0001-9833-097X), chrisberenguer300@gmail.com (Pereira, C.H.B.), fernando.paivajr@ufpe.br (de Paiva JR, F.G.) (0000-0001-5715-3882).
} 
administrativo, estratégico, de comprometimento e de equilíbrio entre trabalho e vida pessoal (MELLO, LEÃO, PAIVA JÚNIOR, 2006).

Existem esforços acadêmicos sendo empreendidos em busca da compreensão acerca da natureza multidisciplinar dos perfis empreendedores (MAN e LAU, 2000; MELLO, LEÃO e PAIVA JÚNIOR, 2006; DRAKSLER e ŠIREC, 2020), ao lado disso, há também necessidade de se discutir o constructo de competências empreendedoras no contexto da contemporaneidade configurado pela profusão das tecnologias da informação e comunicação (TIC). Isso conduz a implicações com respeito ao entendimento dessas competências como formas de serem desenvolvidas modalidades de liderança configuradas por um empreendedor não-atomístico, construtivista e relacional (PAIVA JÚNIOR, 2011), propício ao desenvolvimento de soluções inovadoras demandadas por protagonistas que atuam no desenvolvimento das novas dinâmicas organizacionais que ocorrem em empreendimentos presentes na sociedade da informação (FILHO, SILVA e MUZZIO, 2019).

As empresas de base tecnológica cujo expoente conceitual é a inovação assumem a forma de negócios dirigidos para serviços intensivos em conhecimento (Knowledge Intensive Business Services) - KIBS e passam a compor o cerne das estratégias pautadas em políticas de desenvolvimento territorial (HERAUD, 2016). Logo, parece necessário compreender características distintivas de um perfil empreendedor que emerge do comportamento de líderes de empresas intensivas em tecnologia, suas aptidões e capacidades de atuação frente a cenários de incerteza em meio a coletividades e situações hostis ao empreendedorismo (LIMA et. al, 2017).

O sujeito investigado no estudo é o dirigente de negócios que manifesta comportamento de características empreendedoras e atua em empresas de base tecnológica sediadas no polo tecnológico da Região Metropolitana do Recife. Esse empreendedor tem sido alvo de iniciativas sistemáticas de desenvolvimento setorial no campo das TIC e vem alcançando relevância profissional em âmbito nacional, a considerar que tal Polo Tecnológico tem se estabelecido como alternativa sócio-econômica a arranjos produtivos de tecnologia historicamente consagrados das regiões Sul e Sudeste do Brasil (SILVA, FERNANDES e PAIVA JÚNIOR, 2020).

\section{REFERENCIAL TEÓRICO}

As competências empreendedoras compreendem um grupo de características psicológicas, habilidades e formas de sapiência, influenciadas por vivências, conhecimentos, escolaridade, histórico familiar e componentes demográficos. Logo, o empreendedor apresenta aqui suas competências individuais, sustentadas pela evidência de uma gestão eficiente e eficaz, tais como estratégia, visão e ação, os quais se tornam valores tangíveis e/ou intangíveis no cenário dos empreendimentos inovadores (MAN \& LAU, 2000; ANTONELLO, 2005; BITENCOURT et al, 2016). Portanto, as competências empreendedoras são averiguadas conforme o nível de análise posicionado na esfera individual e dispõem de um processo contínuo de aprendizagem (ZAPIER \& WUNSCH, 2011). Assim, tais circunstâncias de aprendizagem mesclam experiências pessoais e profissionais do indivíduo que empreende seu negócio, vindo esse movimento a expressar a face evolutiva de um processo contínuo de seu desenvolvimento pessoal e profissional.

O arcabouço analítico das competências empreendedoras parte do estudo de Man e Lau (2000), que conduzem uma investigação junto a empreendedores atuantes nas pequenas e médias empresas (PME) de base tecnológica localizadas em Hong Kong e propõem um leque de competências tratadas com ênfase em aspectos comportamentais desses empreendedores, sendo elas esquematizadas em dimensões como competências de oportunidades, relacionamentos, conceituais, administrativas, estratégicas, e de comprometimento. Adicionalmente, o estudo de Mello, Leão e Paiva Júnior (2006) assinala a pertinência da competência de equilíbrio entre trabalho e vida pessoal, trazendo para o debate acadêmico a necessidade de intermediação entre o fazer relacionado ao ofício e aspectos extra organizacionais da esfera das relações privadas e lúdicas do empreendedor.

Os estudos de Ott, Usart e Romero (2015) e Vilória (2017) adotam a perspectiva endógena das competências do século 21 como algo referente ao conjunto de dimensões concebidas como: comunicação, colaboração, habilidades socioculturais, criatividade, pensamento crítico, solução de problemas, produtividade, aprender a aprender, auto direcionamento, planejamento, flexibilidade e adaptabilidade, assunção de riscos, administração de conflitos, senso de iniciativa e empreendedorismo, além da apropriação social de tecnologias da informação e comunicação (TIC).

O conceito de proficiência tecnológica na forma de competências digitais proposto situadas como o conjunto de conhecimentos, habilidades e destreza, proposto por Oberländer, Beinicke e Bipp (2020), permite que indivíduos atuem de forma exitosa no trabalho, sobretudo em relação ao uso intensivo de mídias digitais. Logo, 
esses autores ressaltam a distinção entre conhecimento, habilidade (skill) e destreza (abilities).

O conhecimento é definido como o conjunto de informações necessárias para se garantir que o indivíduo seja qualificado no sentido de executar tarefas relativas a determinado ofício de forma generalizada, a habilidade é identificada como a capacidade de se desempenhar uma tarefa específica. Já a destreza é tomada pela capacidade voltada para a execução de tarefas distintas, aquisição de conhecimento ou desenvolvimento de determinada habilidade de forma virtuosa (OBERLÄNDER, BEINICKE, e BIPP 2020).

O uso do termo expertise tem se mostrado presente no campo do empreendedorismo, reconhecido como o acúmulo de experiências tácitas no que concerne a práticas empreendedoras vivenciadas no cotidiano empresarial do dirigente, em que são distinguidos os indivíduos empreendedores detentores de determinada expertise daqueles tidos como empreendedores neófitos no mundo dos negócios (MARKOWSKA, 2018).

O êxito de pequenas e médias empresas é afetado pelas competências dos empreendedores no esforço por acelerar o desempenho inovador. A partir de um estudo elaborado por Mohsin, Halim e Farhana (2017), na Malásia, revela que há o consenso de que algumas das competências empreendedoras influenciam a capacidade de inovação. Assim, os empreendedores devem ter as competências certas para realizar projetos inovadores. Os autores asseveram que os CEO de PME são aconselhados a ampliar suas competências para fazer seus negócios avançarem, ou correm o risco de ficar para trás no mercado sem fronteiras de hoje.

O referencial teórico empregado neste estudo (MAN e LAU, 2000; MELLO, LEÃO, PAIVA JUNIOR, 2006; OTT, ROMERO e USART, 2015; VILORIA, 2017) remete a um modelo analítico de competências configuradas como: competências de oportunidade: senso de iniciativa e empreendedorismo; competências de relacionamento: comunicação, colaboração, habilidades socioculturais, administração de conflitos; competências conceituais: criatividade, pensamento crítico, solução de problemas, assumir riscos; competências administrativas: flexibilidade e adaptabilidade; competências estratégicas: planejamento; Competências de Comprometimento: produtividade e auto direcionamento; e competências tecnológicas: letramento digital, letramento em tecnologia da informação e comunicação e utilização de tecnologias para realização do trabalho. Dessa forma, elencamos as categorias desses estudos na tabela 1.

Tabela 1: Concepções de Competências Empreendedoras

\begin{tabular}{|c|c|c|}
\hline Competência & Definições & Ocorrências \\
\hline Oportunidade & $\begin{array}{l}\text { Identificar as oportunidades de negócios a partir } \\
\text { de experiências prévias } \\
\text { Avaliar os espaços de mercado não atendidos } \\
\text { Pesquisar oportunidades por meio dos esforços } \\
\text { de marketing } \\
\text { Identificar sinergia com parceiros }\end{array}$ & $\begin{array}{l}\text { Identificação de lacunas não-atendidas } \\
\text { de mercado por meio de operações } \\
\text { comerciais, relacionamentos e } \\
\text { mudanças de cenário }\end{array}$ \\
\hline Relacionamento & $\begin{array}{l}\text { Construir e manter redes de relacionamentos } \\
\text { com stakeholders e Utilizar-se de } \\
\text { comunicabilidade nos relacionamentos pessoais } \\
\text { em meio à atividade profissional. }\end{array}$ & $\begin{array}{l}\text { Construção e manutenção de } \\
\text { relacionamentos de confiança entre } \\
\text { clientes, fornecedores, colaboradores e } \\
\text { demais parceiros } \\
\text { Recorrência a pessoas e grupos de } \\
\text { referência oriundos do cotidiano } \\
\text { pessoal em favor da prática profissional } \\
\text { estabelecida }\end{array}$ \\
\hline Conceitual & $\begin{array}{l}\text { Raciocinar de forma criativa } \\
\text { Inovar } \\
\text { Lidar com o risco } \\
\text { Ter vocação } \\
\text { Ter autonomia } \\
\text { Ter sensibilidade e vontade de aprender }\end{array}$ & $\begin{array}{l}\text { Análise de caminhos alternativos na } \\
\text { busca por otimização de resultados } \\
\text { Diferenciação em processos, mercados, } \\
\text { produtos e tecnologias }\end{array}$ \\
\hline
\end{tabular}




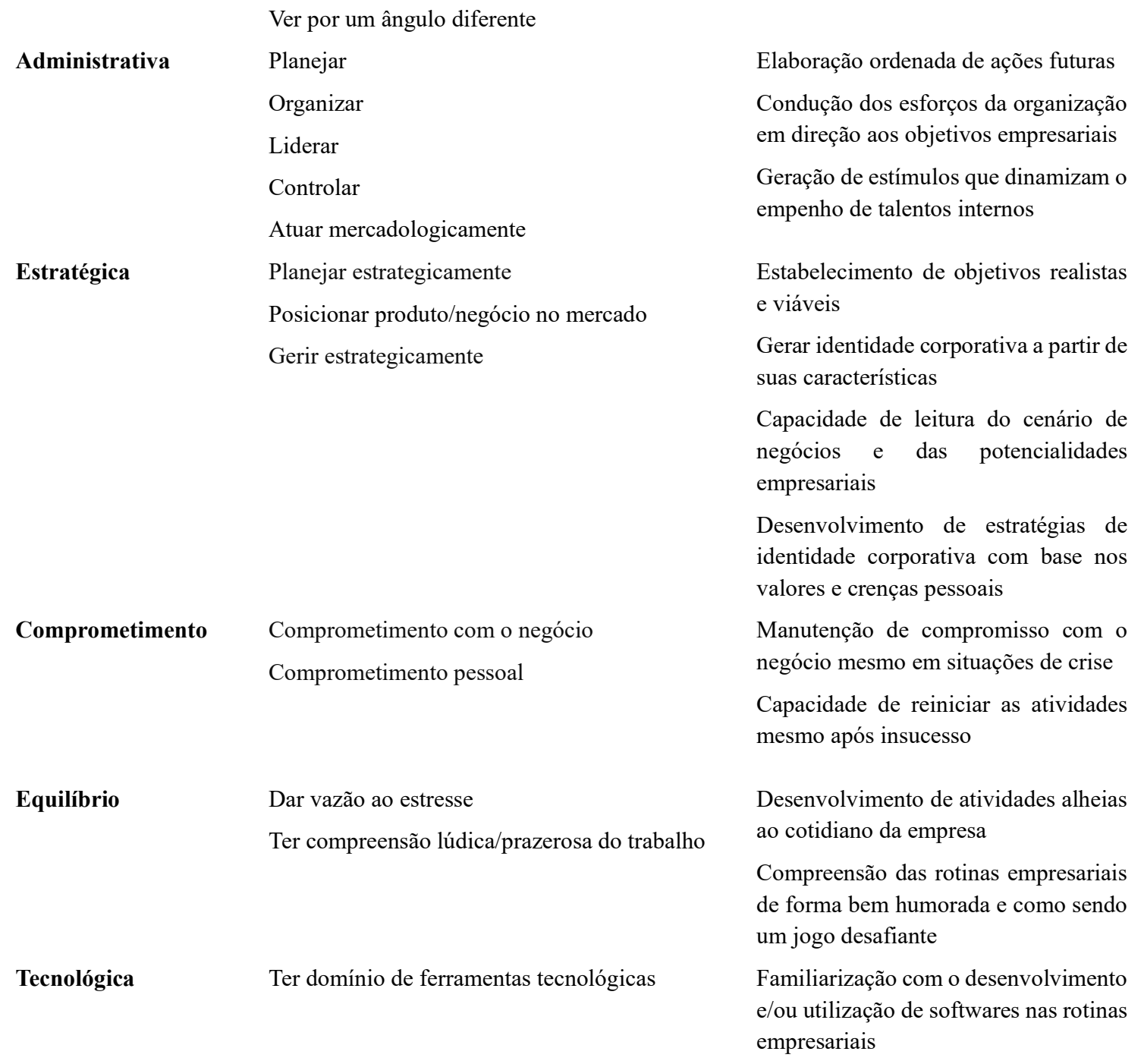

Fonte: Adaptado de Mello, Leão e Paiva Júnior (2006) e Ott, Usart e Romero (2015)

As categorias empíricas apresentadas no referencial teórico (Tabela 1) norteiam as análises e subsidiam as discussões do tópico das análises dos resultados e as considerações temáticas demarcadas nas conclusões.

\section{PROCEDIMENTOS METODOLÓGICOS E ANALÍTICOS}

Este estudo conta com uma natureza qualitativa concebida sob um olhar teórico-empírico de cunho descritivo. O objeto de análise foi extraído dos diálogos de seis dirigentes de empresas de base tecnológica, conforme a tabela 2. Todos os entrevistados contam com pelo menos cinco anos de experiência profissional em empresas intensivas em tecnologia; além disso, o perfil das atividades de atuação dos entrevistados classifica-se como sendo oriundo de empresas desenvolvedoras de softwares, que se configuram como sociedades limitadas e dispõem de um faturamento máximo de 15 milhões, sendo todas elas domiciliadas na Região Metropolitana do Recife (RMR). Tal perfil investigado se justifica pela necessidade de compreensão das competências empreendedoras a partir da perspectiva de empresários com relativa expertise empreendedora, conforme sugere Markowska (2018).

A seleção dos membros entrevistados ocorreu buscando atender aos seguintes critérios de amostragem em que o recorte desses: (I) Ser dirigente de uma empresa de base tecnológica; (II) atuar profissionalmente na RMR (III); ser dirigente de empresa de médio ou grande porte (IV).

No presente estudo, utiliza-se a técnica de amostragem por conveniência, um método de amostragem não- 
probabilística segundo o qual a ênfase na representatividade da amostra é substituída pela amostragem intencional, visando determinada exploração ou discussão temática (BATTAGLIA, 2008). Logo, os resultados apresentados a partir de tal técnica são discutidos no que diz respeito ao constructo como alternativa às representações estatísticas.

Tabela 2 - Perfil dos respondentes chave

\begin{tabular}{llll}
\hline Empresa & Cargo & Grau de Escolaridade & Área da formação \\
\hline E1 & Diretor executivo & Superior Completo & Administração \\
E2 & Diretor executivo & Superior Completo & Direito e Ciências da Computação \\
E3 & Diretor executivo & Especialização & Sistemas da Informação \\
E4 & Diretor executivo & Especialização & Engenharia da Computação \\
E5 & Diretor executivo & Especialização & Ciências da Computação \\
E6 & Diretor executivo & Superior Completo & Ciências da Computação \\
\hline
\end{tabular}

Nota. Fonte: Elaboração própria

As entrevistas foram realizadas individualmente junto aos empreendedores e transcritas respeitando procedimentos éticos da pesquisa nas ciências sociais por meio de protocolos de identificação única $\left(\mathrm{E} 1 \mathrm{~N}^{\circ} 01\right.$ Protocolo 01012016). O protocolo está dividido em três itens principais, o primeiro diz respeito à identificação da empresa, o segundo refere-se à quantidade de perguntas e o último registra o ano da realização da entrevista. Logo, o plano analítico compreende uma análise de conteúdo contemplando o processo de transcrição dos relatos dos entrevistados, codificação dos conteúdos e interpretação de seus significados (BAUER \& GASKELL, 2002).

Os procedimentos metodológicos inserem um conjunto de técnicas de análise das comunicações, sistematizadas por etapas de pré-análise, codificação, categorização e inferência, conforme sugere Bardin (1977), em que a etapa de codificação e ordenação dos dados foi realizada por análise de frequência representativa aos respectivos códigos identificados a partir dos significados emergentes e do referencial teórico abordado neste estudo, tais processos de quantificação e codificação foram auxiliadas pelo uso do software NVivo em sua versão 10 (NETO et. al, 2019) em que se busca identificar agrupamentos de significados pela ocorrência de palavras constantes nos relatos transcritos das entrevistas individuais. Dessa forma, as análises são elucidadas por meio de tabelas de frequência, compondo um total de 124 citações das dimensões sugeridas no estudo (Tabela 3 ).

\section{APRESENTAÇÃO DOS RESULTADOS}

Os resultados estão apresentados visando substanciar a resposta para a pergunta de pesquisa: que competências empreendedoras emergem do comportamento de dirigentes de empresas intensivas em tecnologia domiciliadas da Região Metropolitana do Recife (RMR)? Inicialmente, uma visão geral dos resultados de todas as áreas de competências com identificação de frequência e porcentagem referente ao total, as competências mais relevantes estão destacadas na tabela 1 e, em seguida, há o registro da análise individual dos resultados estratificados por competência, contendo análise, relato, frequências e porcentagens referentes ao total individual.

\subsection{Dimensões das competências empreendedoras}

As competências mais mencionadas pelos entrevistados, de acordo com a tabela 3, são as Competências Conceituais com 1/4 das incidências. Em seguida, constam as Competências Estratégicas correspondendo a 1/5 dos registros e a Competência de Relacionamento representa 1/6 dos conteúdos relatados.

Tabela 3 - Incidência das Competências Empreendedoras

\begin{tabular}{clcc}
\hline Cód. & Classificação & Freq. & $\%$ \\
\hline 10 & Competência de Oportunidade & 4 & $3.5 \%$ \\
$\mathbf{1 1}$ & Competência de Relacionamento & $\mathbf{1 9}$ & $\mathbf{1 5 \%}$ \\
$\mathbf{1 2}$ & Competência Conceitual & $\mathbf{3 0}$ & $\mathbf{2 4 \%}$ \\
13 & Competência Administrativa & 16 & $13 \%$ \\
$\mathbf{1 4}$ & Competência Estratégica & $\mathbf{2 5}$ & $\mathbf{2 0 \%}$ \\
15 & Competência de Comprometimento & 14 & $11 \%$
\end{tabular}




\begin{tabular}{llcc}
16 & Competência de Equilíbrio trabalho / vida pessoal & 4 & $3.5 \%$ \\
$\mathbf{1 7}$ & Competência Tecnológica & $\mathbf{1 2}$ & $\mathbf{1 0 \%}$ \\
\hline
\end{tabular}

Fonte: Elaboração própria

\subsection{Competências de oportunidade}

Na visão de oportunidades de negócios, existe a identificação dos cenários favoráveis, a compreensão dos objetivos organizacionais e atuação junto a potenciais chances de êxito emergentes de uma observação de negócios existentes, sendo essas as características de um perfil empreendedor (MELLO, LEÃO E PAIVA JÚNIOR, 2006).

A Tabela 4 registra que o processo de identificação, avaliação e exploração de oportunidades ocorre por meio de experiências anteriores vivenciadas pelo empreendedor. Tais achados se coadunam com estudos de autores como Venkataraman (1997), Shane e Venkataraman (2000), Hisrich e Peters (2002), Baron, Shane (2007) e Albuquerque e Teixeira (2016), ao destacarem a função das competências de oportunidade como elementos condutores da criação de bens e serviços inovadores. O relato do entrevistado 2 corrobora com essa perspectiva:

Tive quatro empresas, das quais iniciei duas, hoje possuo uma e vou me ater a ela para essa resposta. Foi uma experiência atípica (a abertura da empresa), pois ela nasceu após a desistência do antigo dono em continuar e através de um acordo com locador e locatário do antigo espaço, eu abri o nosso negócio com outros sócios. No Brasil, ocorre que mais do que habilidades, a persistência se faz necessária mediante tantos entraves burocráticos, mas conseguimos com muita dificuldade criar o projeto, avaliar mercado, realizar reformas $e$ abrir o empreendimento em apenas três meses, sinceramente, crédito a isso a nossa existência prévia com empresas de TI - E2.

A identificação de oportunidades de negócios no cenário tecnológico também é resultado na capacidade de o empreendedor identificar oportunidades emergentes de lacunas situacionais no âmbito organizacional. Essa expertise empreendedora é corroborada com a perspectiva de Markowska (2018) ao destacar a pertinência do acúmulo de conhecimentos tácitos por parte do empreendedor a partir de ressignificações que surgem de suas experiências passadas.

Tabela 4: Incidência das Competências de Oportunidade

\begin{tabular}{|c|c|c|c|}
\hline Cód. & Classificação & Freq. & $\%$ \\
\hline 101 & Identificar as oportunidades de negócios a partir de experiências prévias & 3 & $75 \%$ \\
\hline 102 & Avaliar os espaços de mercado não atendido & - & $\mathbf{0 \%}$ \\
\hline 103 & Pesquisar oportunidades por meio dos esforços de marketing & - & $\mathbf{0 \%}$ \\
\hline \multirow[t]{2}{*}{104} & Identificar sinergia com parceiros & 1 & $25 \%$ \\
\hline & & 04 & $100 \%$ \\
\hline
\end{tabular}

Fonte: Elaboração própria

\subsection{Competências de relacionamento}

A competência de relacionamento é reconhecida como capacidade de interlocução com múltiplos atores que auxiliam a potencializar a identificação e absorção de oportunidades de negócio em meio a algum cenário favorável do mercado. Logo, tal competência é caracterizada pela habilidade relacional catalizadora de formas distintas de capital social, econômico-financeiro e intelectual. (LIN, 2001; MELLO, LEÃO, PAIVA JUNIOR, 2006).

No âmbito das organizações inseridas em ecossistemas de inovação, as parcerias com stakeholders são configuradas pelo intercâmbio de conhecimento entre os atores envolvidos que operam no âmbito de uma rede social. Isso ocorre na forma de aprendizado por interação característica de ambientes compartilháveis e exemplo dos ecossistemas de inovação, o que pressupõe certa seletividade na construção de parcerias, uma vez que tais 
interações se baseiam na confiança mútua e cooperação, recursos construídos ao longo do tempo (LUNDVALL, 1992; BACON; WILLIAMS, e DAVIES, 2020). Por outro lado, existe uma tensão complexa com respeito à gestão do paradoxo referente às lógicas de cooperação e competição funcionando em movimentos simultâneos das atividades interorganizacionais (GRIYAWALI et al, 2016).

A tabela 5 demonstra indícios da utilização de relacionamento como fonte de negócios, fato antecedido por Mello (2017) em que a reputação corporativa representa um mecanismo institucional para minimizar os riscos associados ao parceiro e aqueles que incentivam a geração de negócio entre as partes, conforme ilustração apresentada no relato do entrevistado 1: “...o fraco relacionamento entre os colaboradores e os clientes era contínuo na empresa que prestava serviço, e esse foi o ponto a ser desenvolvido em minha empresa, onde atuo com a maior transparência e confiança possivel...".

Tabela 5: Incidência das Competências de Relacionamento

\begin{tabular}{|c|c|c|c|c|}
\hline Cód. & Classificação & & Freq. & $\%$ \\
\hline 111 & Construir e manter redes de relacionamentos com stakeholders & & 6 & $47 \%$ \\
\hline \multirow[t]{2}{*}{112} & Utilizar-se dos relacionamentos & & 8 & $53 \%$ \\
\hline & & TOTAL & 19 & $100 \%$ \\
\hline
\end{tabular}

Fonte: Elaboração própria

\subsection{Competências conceituais}

As oportunidades que surgem dos ambientes externo e interno da organização constituem etapas normais em um processo de decisão com respeito a determinado empreendimento de perfil inovador, em que cabe ao empreendedor driblar dificuldades ou desenvolver respostas rápidas e intuitivas a problemas emergentes (MAN \& LAU, 2000).

A abertura de novos nichos de mercado, tanto com produtos e serviços novos como antigos são função desses indivíduos, tornando-os eficientes para ter a capacidade de avaliar situações de risco decorrentes de suas decisões, além de propiciar às empresas o uso do capital intelectual e a capacidade de inovar, pois aumenta a velocidade, frequência e magnitude da inovação da empresa (MELLO, LEÃO, PAIVA JUNIOR, 2006; LANE, KOKA E PATHAK, 2006; CASSOL, ZAPALAI E CINTRA, 2017).

Conforme a tabela 5 , a capacidade de inovar, a relação com o risco e a sensibilidade e o raciocínio de forma criativa se mostram evidentes, pois, a capacidade de avaliar riscos por parte do empreendedor é basilar no reforço a seu controle com respeito ao ato de empreender, em que essa colocação pode ser averiguada no relato do entrevistado 2:

"Hoje se fala de vários tipos de inteligências, acredito que o empreendedor é o indivíduo que consegue reunir sua eficiência em alguns campos conseguindo compreender suas limitações, buscando contornar através de estudos, dedicação ou até contratando pessoas que consigam suprir sua deficiência, focado no que de fato é importante para o negócio em si”- E2.

Tabela 6: Incidência das Competências Conceituais

\begin{tabular}{|c|c|c|c|c|}
\hline Cód. & Classificação & & Freq. & $\%$ \\
\hline 121 & Racionar de forma criativa & & 8 & $27 \%$ \\
\hline 122 & Inovar & & 7 & $23 \%$ \\
\hline 123 & Lidar com o risco & & 11 & $36 \%$ \\
\hline 124 & Ter vocação & & 2 & $7 \%$ \\
\hline 125 & Ter autonomia & & - & $\mathbf{0 \%}$ \\
\hline \multirow[t]{2}{*}{126} & Ter sensibilidade e vontade de aprender & & 2 & $7 \%$ \\
\hline & & TOTAL & 30 & $100 \%$ \\
\hline
\end{tabular}


Nota. Fonte: Elaboração própria

\subsection{Competências administrativas}

As competências administrativas estão associadas a "homens eficientes" que remontam às concepções da administração clássica (TAYLOR, 1970). Eles são caracterizados como indivíduos qualificados para alocação de talentos, recursos físicos, financeiros e tecnológicos, criando, assim, mecanismos de planejamento, organização, comando, motivação, delegação e controle ágil (MAN \& LAU, 2000, MINTZBERG, AHLSTRAND, \& LAMPEL, 2000; TAYLOR \& QUINN, 2001; RIBEIRO et al., 2016).

No que tange às competências Administrativas, existe um foco conceitual centrado no comportamento de liderança, conforme revelado pelo entrevistado 3: “... acredito que uma empresa de médio porte se sustente por causa de seus diretores, a liderança, o planejamento e a presença são fundamentais para o sucesso ..." fato que reafirma a proposição de Birley e Mazyka (2001) e Machado et al. (2016), quando declaram que o empreendedor tenta criar valor, diminuindo os recursos disponíveis, o que tende a implicar em maiores riscos com sua atividade operacional. Assim, esses autores propõem o desenho de estratégias de treinamento dirigidas para o desenvolvimento de competências dos trabalhadores atuando em diferentes setores.

Tabela 7: Incidência das Competências Administrativas

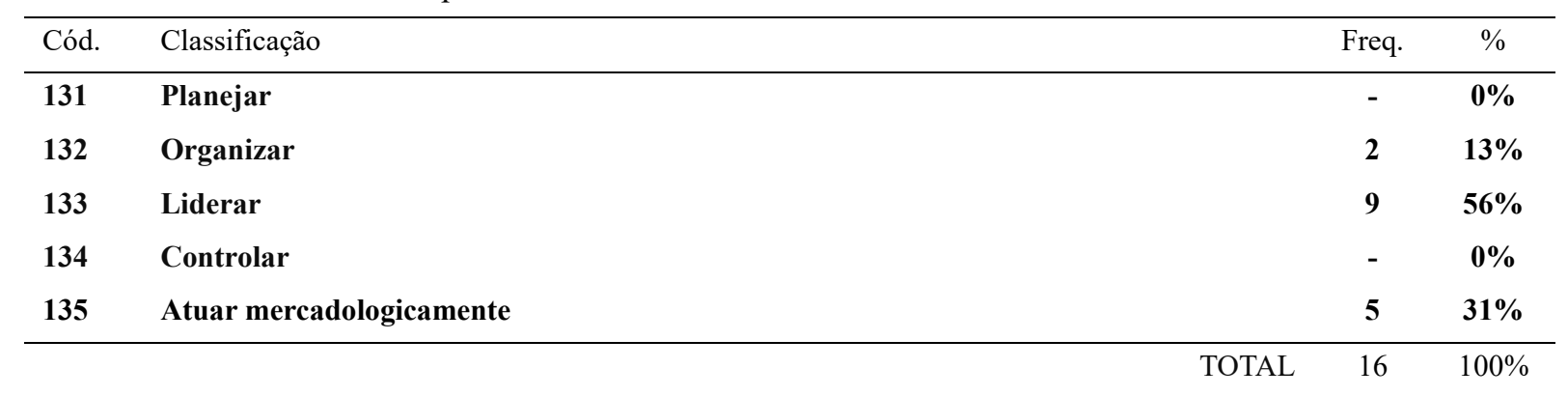

Nota. Fonte: Elaboração própria

\subsection{Competências estratégicas}

Os empreendedores eficientes visualizam panoramas de tempo no status de prazos curtos, médios e longos, em que esses agentes planejam suas tarefas de acordo com os objetivos, em conformidade com posicionamentos e prazos realistas. Porém, eles precisam estar atentos às mudanças externas e internas para ajustar os grupos de trabalho em função das direções corretas, e efetuar uma gerência da organização atenta aos seus níveis de complexidade (VENEGAS, THILL, DOMNANOVICH, 2017)

O direcionamento estratégico norteia e acrescenta a confiança do administrador em cenários futuros de ação e alcance de resultados plausíveis, o qual, por sua vez, orienta a sua equipe, ao ser apresentada imagem de profissionalismo junto aos clientes, aos concorrentes e aqueles responsáveis pelos orçamentos financeiros (KERNS, 2002; BOCCIARDI, et. al, 2017). A Tabela 8 demonstra certa relevância do planejamento estratégico, fato ilustrado no relato do entrevistado 4:

"Sim, o planejamento estratégico é direcionado as pessoas desta área, porém, às vezes, os seus colaboradores precisam de uma chacoalhada para enxergar o que o dono está enxergando. O dia-a-dia atrapalha o pensamento sistêmico, assim eles ficam mais alinhados com os objetivos da empresa" - E4.

A necessidade de se planejar estrategicamente se configura como uma competência pertinente, uma vez que o empreendedorismo no âmbito tecnológico é permeado por situações de incerteza demarcadas pela complexidade de cenários inerente ao ofício, sendo esse fato caracterizado por necessidades de serem avaliadas alternativas de viabilização comercial e da proposição de ações empresariais frente a externalidades incidentais (CLEARY, 2017; DRAKSLER e SIREC, 2020). 
Tabela 8: Incidência das Competências Estratégicas

\begin{tabular}{|c|c|c|c|}
\hline Cód. & Classificação & Freq. & $\%$ \\
\hline 141 & Planejar estrategicamente & 11 & $44 \%$ \\
\hline 142 & Posicionar o negócio / produto no mercado & 8 & $32 \%$ \\
\hline 143 & Gerir estrategicamente & 6 & $24 \%$ \\
\hline
\end{tabular}

Nota. Fonte: Elaboração própria

\subsection{Competências comprometimento}

As bases do comprometimento organizacional estão associadas a relações com as equipes de colaboradores que disponham de comprometimento afetivo com suas lideranças, quando Allen e Meyer (1990) afirmam que a dimensão do comprometimento dispõe de três bases: afetiva, instrumental e normativa. Aqueles que revelam comprometimento calculado permanecem atuando na empresa visando os recursos materiais, os que revelam comprometimento normativo permanecem operando na organização por se sentirem obrigados por comodidade, o que afeta o desempenho do grupo.

O comprometimento com o trabalho é oriundo de contratos psicológicos entre os líderes das organizações e seus colaboradores, como essência do comportamento organizacional (TENBRUNSEL, 2002). Não obstante, Demo (2003) ressalta que os estudos sobre comprometimento têm se concentrado no foco organizacional e na base afetiva. Em paralelo, o relato do entrevistado 6 confirma as constatações desse estudo: “... quando você tem afeição pelo seu negócio você procurará passar mais tempo dentro dele e isso é a chave para que outros seguiam o seu exemplo, torne-se presente e seus colabores o seguirão ...”. - E6.

A tabela 9 demonstra o destaque do comprometimento calibrado entre a vida pessoal e a profissional do empreendedor, o que se coaduna com o estudo de Karutko e Hodgetts (1995) e Martins et al (2017). Logo, a crença vinculada a motivação, intenção, sentimento e confiança são elementos propulsores da expansão de determinado negócio e, com isso, os benefícios resultantes. O relato do entrevistado 2 "Tive 4 empresas, das quais 2 iniciei, hoje possuo 1. Não tenho vergonha de ter falido 3 vezes, agora estou satisfeito com os resultados alcançados e eu amo mais que nunca a (****) e a valorizo bem mais. Agora eu sei como é difícil abrir e fácil fechar uma empresa" - E2.

Tabela 9: Incidência das Competências Comprometimento

\begin{tabular}{llrc}
\hline Cód. & Classificação & Freq. & $\%$ \\
\hline $\mathbf{1 5 1}$ & Comprometimento com o negócio & $\mathbf{7}$ & $\mathbf{5 0 \%}$ \\
$\mathbf{1 5 2}$ & Comprometimento pessoal & $\mathbf{7}$ & $\mathbf{5 0 \%}$ \\
\hline & & TOTAL & 14 \\
\hline
\end{tabular}

Nota. Fonte: Elaboração própria

\subsection{Competências de equilíbrio trabalho/vida pessoal}

O comprometimento do empreendedor com seus propósitos empresariais sem sacrificar suas aspirações individuais no âmbito extra-organizacional se revela fator relevante para a obtenção de êxito em iniciativas empreendedoras (TIPU, RYAN, 2016). Logo, essa reflexão parte de dirigentes de empresas intensivas em tecnologia que atuam em conformidade com o pressuposto ganha-ganha, em que há o elo entre a vida pessoal do indivíduo e organização (QUEL, 2008). O relato do entrevistado 5 corrobora com Quel (2008) quando afirma que "[...] no final do dia a caminho de casa ter a sensação de dever comprido é excelente, todavia chegar em casa depois de um dia de trabalho pesado e poder brincar com meus filhos, não tem preço, é a maior satisfação [...]" E5.

Uma competência que demonstra equilíbrio entre suas classificações, como visto na tabela 10, que circula entre dar vazão ao estresse e ter uma compreensão lúdica/prazerosa do trabalho. Há novas metodologias de 
comunicação com as equipes que as tornam mais produtivas e ágeis, que garantem a delegação das tarefas e a busca da satisfação nas atividades da rotina da empresa (STEIBER, ALÄNGE, 2013; NOGUERA, GUERREROROLDÁN, MASÓ, 2018).

Tabela 10: Incidência das Competências de Equilíbrio Trabalho/Vida Pessoal

\begin{tabular}{|c|c|c|c|}
\hline Cód. & Classificação & Freq. & $\%$ \\
\hline 161 & Dar vazão ao estresse & 2 & $50 \%$ \\
\hline 162 & Ter uma compreensão lúdica / prazerosa do trabalho & 2 & $50 \%$ \\
\hline
\end{tabular}

Nota. Fonte: Elaboração própria

\subsection{Competências tecnológicas}

A competência tecnológica apresenta incidências em todas as entrevistas, certificando o valor da tecnologia na absolvição de valores, crenças, conhecimento, habilidades e atitudes (VILORIA, 2017). Além disso, Viloria et. al. (2012) consagra o termo "competência digital" que exige a compreensão e conhecimento do letramento em tecnologias da informação e comunicação, bem como a identificação de oportunidades advindas dos potenciais usos das tecnologias em situações cotidianas do profissional e social, além de demandar o uso de informações de forma crítica e sistemática a fim de avaliar sua relevância social e científica (OTT, USART e ROMERO, 2015; VILÓRIA, 2017). A percepção acerca da pertinência de tal competência pode ser observada na fala de E1: "Tecnologia é quem dita o futuro, sem ela não conseguiríamos trabalhar com a mesma eficácia, ela está inserida em todas as áreas de conhecimento, hoje um médico não consegue fazer uma cirurgia sem antes utilizar da tecnologia ..."

Essas competências de orientação instrumental se fazem pertinentes diante do cenário tecnológico, pois, na perspectiva dos empreendedores de base tecnológica, é desejável que tomadas de decisão gerenciais sejam fundamentadas em conhecimentos relacionados ao fazer tecnológico e na identificação de demandas que partem de lacunas de experiências de usuário (MARKOWSKA, 2018).

Tabela 11: Incidência das Competências Tecnológicas

\begin{tabular}{|c|c|c|c|c|}
\hline Cód. & Classificação & & Freq. & $\%$ \\
\hline 171 & Utilização de tecnologias para realização do trabalho & & 6 & $\mathbf{5 0 \%}$ \\
\hline 172 & Letramento em Tecnologia da Informação e Comunicação & & 3 & $25 \%$ \\
\hline \multirow[t]{2}{*}{173} & Letramento em computação digital & & 3 & $25 \%$ \\
\hline & & TOTAL & 12 & $100 \%$ \\
\hline
\end{tabular}

Nota. Fonte: Elaboração própria

\section{CONSIDERAÇÕES FINAIS}

Este estudo buscou analisar e identificar as competências empreendedoras emergentes no comportamento de empreendedores atuantes em empresas de base tecnológica da Região Metropolitana do Recife (RMR), estado de Pernambuco. Dessa forma, os resultados foram apresentados visando substanciar a resposta para a pergunta de pesquisa: quais as competências empreendedoras que emergem do comportamento de dirigentes de empresas intensivas em tecnologia domiciliadas da Região Metropolitana do Recife (RMR)? Os resultados apontam para uma priorização das competências conceituais, estratégicas e de relacionamentos. Tais achados evidenciam a necessidade de serem desenvolvidos conhecimentos voltados para a capacidade de abstração conceitual e leitura sistêmica frente a cenários complexos caracterizados pelas transformações inerentes ao setor de desenvolvimento tecnológico. Além disso, a competência relacional emerge como fator de relevância na construção de parcerias comerciais e capacidade de interação mediante o ambiente de trabalho. 
O estudo tomou ainda como base em categorias anaíticas inseridas em modelos analíticos dos estudos das competências empreendedoras, as quais nos remetem a tópicos inspiradores de novos estudos, tais como: comunicação, colaboração, habilidades socioculturais, criatividade, pensamento crítico, solução de problemas, produtividade, aprender a aprender, auto direcionamento, planejamento, flexibilidade e adaptabilidade, assunção de riscos, administração de conflitos, senso de iniciativa e empreendedorismo.

Uma contribuição do estudo reside na apresentação das competências tecnológicas como categoria de análise, uma vez que a atuação do dirigente num setor permeado por novas tecnologias pode demandar conhecimentos técnicos operacionais de suporte a tomadas de decisão. Por outro lado, os gestores não expressam tanto sua relevância, quando colocada em comparação com as competências conceituais, estratégicas e de relacionamento. A necessidade de conhecimento quanto ao uso de ferramentas tecnológicas para a realização das atividades profissionais emerge como uma contribuição do estudo, de forma que estudos futuros podem investigar a pertinência das competências tecnológicas na construção de um perfil empreendedor, ampliando o conhecimento acerca das especificidades demandadas pela profusão tecnológica.

Embora tenham sido mostrados aspectos reveladores sobre o perfil empreendedor de base tecnológica, a investigação, em Pernambuco, é necessária o desenvolvimento de estudos com a temática das competências empreendedoras em outras regiões do Brasil que possam revelar a configuração daquelas competências predominantes em comportamento de líderes operando em setores diversos como saúde, educação, transportes e mecânica, localizados em suas respectivas regiões.

\section{REFERÊNCIAS}

ALBUQUERQUE, A. da R. P.; TEIXEIRA, R. M. O Processo de Identificação e Exploração de Oportunidade Empreendedora com Base no Modelo de Aprendizagem Organizacional 4i. Revista de Ciências da Administração. v. 18, n. 44, p. 25- 37. 2016.

ALVES FILHO, L. C.; SILVA, A. B.; MUZZIO, H. Criatividade e Desenvolvimento de Competências Gerenciais em Empresas de Base Tecnológica. Revista Economia \& Gestão, v. 19, n. 52, p. 24-42, 2019.

ANTONELlo, C. S. A metamorfose da aprendizagem organizacional: Uma revisão crítica. In: RUAS, R. L.; ANTONELLO, C. S.; BOFF, L. H. e colaboradores. Os novos horizontes da gestão: Aprendizagem organizacional e competências. Porto Alegre: Bookman. p. 12-33. 2005.

ASSUNÇÃO, B. YLUSKA. Qualificação profissional ou Competências para o Mercado Futuro? Future Studies Research Journal: Trends and Strategies, v. 8, n. 1, p. 175-207, Janeiro-Junho. 2016.

BACON, Emily; WILLIAMS, Michael D.; DAVIES, Gareth. Coopetition in innovation ecosystems: A comparative analysis of knowledge transfer configurations. Journal of Business Research, v. 115, p. 307-316, 2020.

BARDIN, L.. Análise de conteúdo. Lisboa: Edições 70, 1977.

BARON, R. A.; SHANE. S. A. Empreendedorismo: uma visão do processo. São Paulo: Thomson Learning. 2007.

BAUER, M. W., \& Gaskell, G. Pesquisa qualitativa com texto, imagem e som: um manual prático. Petrópolis: Vozes. 2002.

BIRLEY, S., \& MUZYKA, D. F. Dominando os desafios do empreendedor. São Paulo: Makron Books. 2001.

BOCCIARDI, F.; CAPUTO, A.; FREGONESE, C.; LANGHER, V.; SARTORI, R. Career adaptability as a strategic competence for career development: An exploratory study of its key predictors. European Journal of Training and Development, v. 41, n. 1, p. 67-82, 2017.

BATTAGLiA, M. Convenience sampling. In: Lavrakas (Org.): Encyclopedia of Survey Research Methods. Vol. 2., $1^{a}$ ed., p.148-149. California: Sage Publications. 2008.

CASSOL, A.; ZAPALAI, J.; CINTRA, R. F. Capacidade absortiva como propulsora da inovação em empresas incubadas de Santa Catarina. Revista Ciências Administrativas, v. 23, n. 1, p. 9-41. 2017.

COOPER, R. G.; SOMMER, A. F. Agile-Stage-Gate: New idea-to-launch method for manufactured new products is faster, more responsive. Industrial Marketing Management, v. 59, p. 167-180, 2016.

DEMO, G., de R. M., P., \& ROURE, P. Políticas de gestão de pessoas, comprometimento organizacional e satisfação no trabalho na livraria cultura/people management policies, organizational commitment and job satisfaction at the livraria cultura bookshop/políticas de gestión de personas, compromiso organizacional y satisfacción en el trabajo en la librería cultura. Revista Alcance (Online), v.20, n.2, p. 217-237. 2013. 
DRUCKER, P. Sociedade pós-capitalista. São Paulo: Pioneira. 2002.

FREITAS, R. K.; TEIXEIRA, R. M. Identificação de Oportunidades Empreendedoras por Mulheres. Revista Economia \& Gestão, v. 16, n. 44, p. 81-108. 2016.

GELLATLY, I. R.Affective and continuance commitment to the organization: evaluation of measures and analysis of concurrent and timelagged relations. Journal of Applied Psychology, v. 75, n. 6, p. 710-720. 1990.

GONDIM, S. M. e COLS, G. Perfil profissional, formação escolar e mercado de trabalho segundo a perspectiva de profissionais de Recursos Humanos. Revista Psicologia: organizações e trabalho. São Paulo, Vol. 10, n. p. 119 152. 2003.

HISRICH, R. D.; PETERS, M. P. Entrepreneurship.New York: McGraw Hill. 2002.

KERNS, C. D. An entrepreneurial approach to strategic direction setting. Business Horizons, v.45, n.4, 2-6. 2002.

LANE, P. J., KOKA, B. R., \& PATHAK, S. The reification of absorptive capacity: A critical review and rejuvenation of the construct. Academy of management review, v.31, n.4, p.833-863, 2006.

LIN, N. Social capital, a theory of social structure \& action. Port Chester. Cambridge University Press. 2001.

LOPEZ, V; SAYERS, J. M.; CLEARY, M. Competitiveness in the Workplace: Attributes and Team Benefits. Issues in Mental Health Nursing, v. 38, n. 6, p. 523-525, 2017.

LUNDVALL, B. National systems of of innovation: towards a theory of innovation and interactive learning. London, UK: Printer, 1992.

MACHADO, H. P. V., GAZOLA, S., DOS SANTOS FABRÍCIO, J., \& ANEZ, M. E. M. Mulheres Empreendedoras: Razões e Dificuldades para Criação de Empresas. Revista de Administração Mackenzie, v.17, n.3. p.102-122. 2016.

MAN, T. W. Y., LAU, T., \& CHAN, K. F. The competitiveness of small and medium entreprises: a conceptualization with focus on entrepreneurial competencies. Journal of Business Venturing, $n$. 17, v.2, 123-142. 2002.

MAN, T. W. Y.; LAU, T. The context of entrepreneurship in Hong Kong - an investigation through the patterns of entrepreneurial competencies in contrasting industrial environments. Journal of Small Business and Enterprise Development. V.12, n.4, p.464-481. 2005.

MARKOWSKA, M. The role of action-control beliefs in developing entrepreneurial expertise. Journal of Small Business and Enterprise Development, v.25, n.2, p.222-240, 2018.

MARTINS, D. M., FARIA, A. C., PREARO, L. C., \& ARRUDA, A. G. S. The level of influence of trust, commitment, cooperation, and power in the interorganizational relationships of Brazilian credit cooperatives. Revista de Administração, v.52, n.1, 47-58. 2017.

MARTINSEN, Ø. L.; FURNHAM, A. Cognitive style and competence motivation in creative problem solving. Personality and Individual Differences, v. 139, n. November 2018, p. 241-246, 2019.

MELLO, C. M. A Influência das Instituições no Processo de Construção da Confiança Interorganizacional. Organizações \& Sociedade, v.24, n.81, p.343-360. 2017.

MELlO, S. C. B. ; LEAO, A. L. M. S. ; PAIVA JUNIOR., F. G. Competências Empreendedoras de Dirigentes de Empresas Brasileiras de Médio e Grande Porte que atuam em Serviços da Nova Economia. RAC. Revista de Administração Contemporânea, v. 10, p. 47-69. 2006.

MEYER, J. P.; ALLEN, N. J.; GELLATLY, I. R. Affective and continuance commitment to the organization: evaluation of measures and analysis of concurrent and timelagged relations. Journal of Applied Psychology, v. 75, n. 6, p. 710-720, 1990.

MOHSIN, Ainul Mohsein B. Abdul; HALIM, Hasliza A.; FARHANA, Nadia. Assessing the role of entrepreneurial competencies on innovation performance: A partial least squares (PLS) approach. The Journal of Business Inquiry, v. 16, n. 1, p. 88-101, 2017.

NETO, A. C. N., MADURO, M. R., ARAÚJO, P. C. D., \& BITTENCOURT, M. A. Estratégias de treinamento e desenvolvimento a partir do uso das trilhas de aprendizagem por competências: Proposta para uma instituição de ensino superior. REVISTA DE ADMINISTRAÇÃO DE RORAIMA (RARR), v.6, n.2, 361-384. 2016.

NOGUERA, I.; GUERRERO-ROLDÁN, A. E.; MASÓ, R. Collaborative agile learning in online environments: Strategies for improving team regulation and project management. Computers and Education, v. 116, p. 110 
$129,2018$.

OTT, M.; USART, M.; ROMERO, M. Can serious games contribute to developing and sustaining 21 st century skill. Games and Culture v. 10, n 2, p. 148-177. 2015.

QUEL, L. F. Alinhamento de competências em instituições de ensino superior: um estudo de caso na rede privada. Revista de Gestão, v. 15, n. especial, p. 63-74. 2008.

RIBEIRO, A. R. B., SILVA, F. F., SANTOS, M. V. N., BARBOSA, C. F. Fatores que Contribuem para o Sucesso de Empresas de Base Tecnológica: um Estudo Multicasos em Incubadoras de Pernambuco. Revista Eletrônica de Estratégia \& Negócios, v.9, n.2, p.208-233, 2016.

SHANE, S.; VENKATARAMAN, S. The promise of entrepreneurship as a field of research. Academy of Management Review, v. 25, n. 1, p. 217-226, 2000.

SILVA, A. D. F.; FERNANDES, N. C. M.; PAIVA JUNIOR, F. G. Um arranjo produtivo local sob a perspectiva da teoria da regulação cultural: o caso do Porto Digital englobando o Portomídia. Organização \& Sociedade, v. 27, n. 93, p. 292-313, 2020 .

SOUZA NETO, R. A; DIAS, F. G; SILVA, R. R; RAMOS, A. S. M. . Efeitos dos Softwares de Análise de Dados Qualitativos na Qualidade de Pesquisas. RAC., v. 23, n. 3, p. 373-394, 2019.

STEIBER, A.; ALÄNGE, S. A corporate system for continuous innovation: The case of Google Inc. European Journal of Innovation Management, v. 16, n. 2, p. 243-264, 2013.

TAYLOR, F. W. \& QUINN, J. B. O processo da estratégia (2a ed). Porto Alegre: Bookman. 2001.

TAYLOR, F. W. Princípios de Administração Científica. 7.ed. São Paulo: Atlas. 1970.

TENBRUNSEL, A. E. Handbook de Estudos Organizacionais. São Paulo: Atlas. 2002.

TIPU, S.; RYAN, J. Predicting entrepreneurial intentions from work values: implications for stimulating entrepreneurship in UAE national youth. Management Decision, v. 54, n. 3.p. 1-26, 2016.

VENEGAS, B. C, THILL, K., DOMNANOVICH, J. The Importance of Strategic Competence in HRM: Evidence from Austria, Czech Republic, Hungary and Slovakia. Journal of Eastern European and Central Asian Research (JEECAR), v.4, n.2,p.1-11. 2017.

VENKATARAMAN, S. The distinctive domain of entrepreneurship research: An editor's perspective. In KATZJ.; BROCKHAUS R. (Eds.), Advances in entrepreneurship, firm emergence and growth, Greenwich, CT: JAI Press, v. 3, p. 119-138. 1997.

VILORIA, H. A. Desarrollo de competencias emprendedoras en docentes de universidades públicas autónomas/Development of Entrepreneurial skills for innovation in of autonomous public universities. Revista Encuentros, v.15, n.1, p. 133-146, 2017.

VILORIA H. A, VILLALOBOS F., ESPINOSA A. Redes sociales, competencias tecnológicas y producción intelectual de los posgrados en Comunicación venezolanos. Revista Encuentros, v. 11, n. 1. Universidad Autónoma del Caribe, Colombia. 2012. 